\title{
Actividad microbial en sustratos y análisis de crecimiento en almácigos de tomate en Guanacaste, Costa Rica
}

\author{
Microbiological activity in substrates and growth analysis \\ of tomato seedlings in Guanacaste, Costa Rica
}
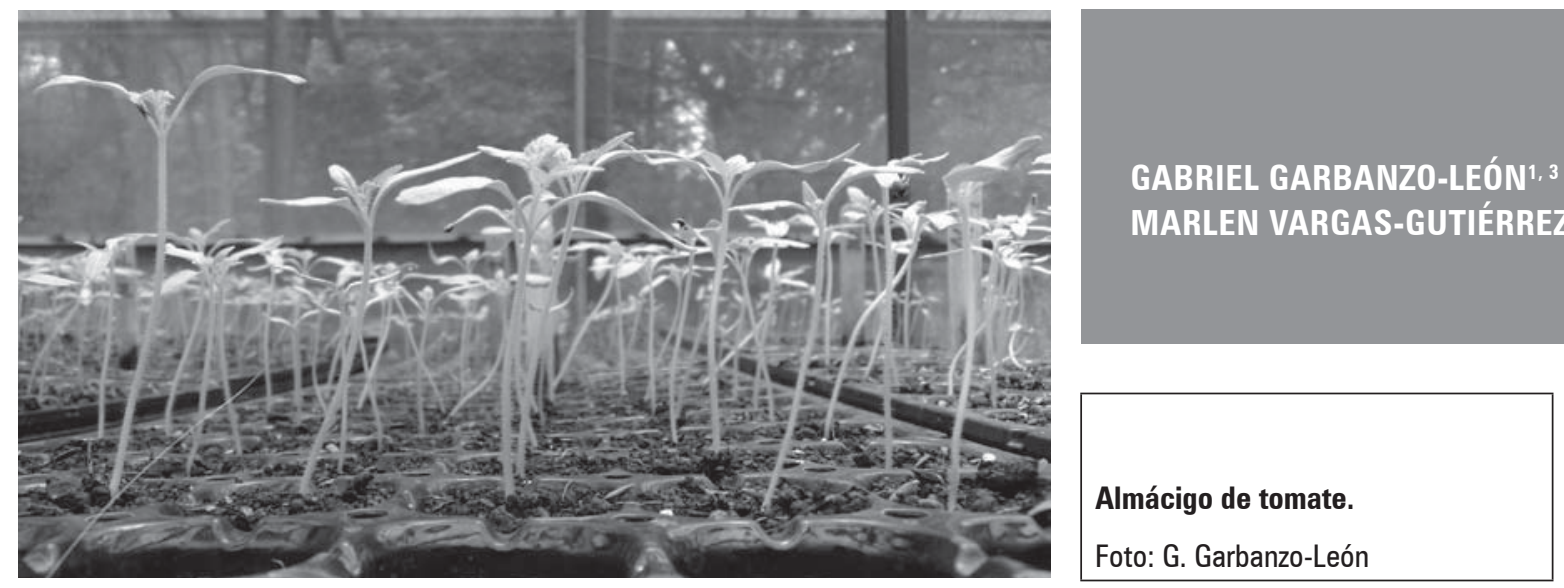

\section{RESUMEN}

Se evalúo el efecto de 10 mezclas de sustratos para almácigos, elaborados con una base de un $50 \%$ de: bocashi, compost y lombricompost, luego estos se mezclaron en una proporción de $25 \%$ con arena, suelo, fibra de coco y granza de arroz. Se midió unidades formadoras de colonias (UFC/g) de hongos, actinomicetos y bacterias, tasa de crecimiento relativo (TCR) y tasa de crecimiento de cultivo (TCC) en plantas de tomate (Solanum lycopersicum) en Liberia, Guanacaste (Costa Rica). El diseño experimental fue un modelo irrestricto al azar, las ufc se evaluaron antes de la siembra de almácigos y los pesos secos para el cálculo de las TCR y TCC se evaluaron a los 15, 22 y 29 días después de siembra. La menor concentración de ufc de hongos ( $<10^{4} \mathrm{UFC} / \mathrm{g}$ ) se presentó en las mezclas $50 \%$ bocashi $+25 \%$ lombricompost $+25 \%$ granza; $50 \%$ lombricompost $+25 \%$ arena $+25 \%$ suelo y $50 \%$ compost $+25 \%$ bocashi $+25 \%$ fibra de coco $(50 \mathrm{CBF})$. El mayor peso se encontró en los tratamientos $50 \%$ bocashi $+25 \%$ compost $+25 \%$ fibra de coco $(50 \mathrm{BCF})$ y $50 \mathrm{CBF}$ significativamente $(P<0,01)$. La TCR en la mezcla $50 \%$ bocashi $+25 \%$ arena $+25 \%$ suelo (50BAS) fue un $47 \%$ más alta al compararlas al testigo (peat moss), mientras que el tratamiento 50CBF presentó la mayor TCC significativamente. Se concluye que las mezclas 50BCF, 50BAS y 50CBF mostraron las mejores condiciones de crecimiento para las plántulas de tomate y el peat moss (Sphagnum sp.) se encontró entre las cinco mezclas menos productivas.

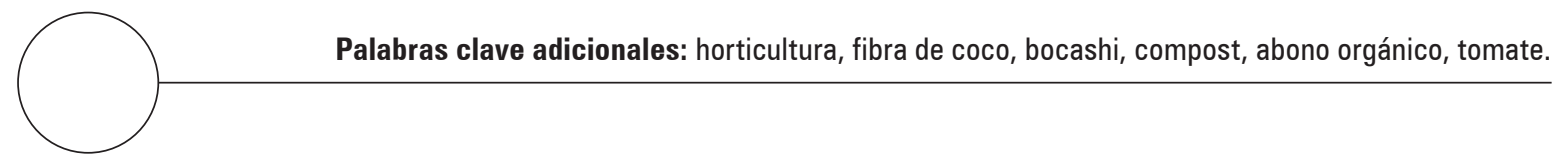

\footnotetext{
Escuela de Agronomía, Centro de Investigaciones Agronómicas, Universidad de Costa Rica, San Pedro (Costa Rica).

2 Carrera de Agronomía, Universidad de Costa Rica, sede regional de Guanacaste, Guanacaste (Costa Rica).

3 Autor para correspondencia. jgabriel.garbanzo@gmail.com
} 


\section{ABSTRACT}

The effect of ten mixtures of substrates for seedlings was evaluated. The mixtures were prepared with bocashi, compost and vermicompost, which was used at $50 \%$, then mixed at a ratio of $25 \%$ sand, soil, coconut fiber and rice husks. The measured variables included total colony-forming units (CFU/g) of fungi, actinomycetes and bacteria, relative growth rate (RGR) and crop growth rate (CGR) in tomato (Solanum lycopersicum) plants. The experiment was evaluated in Liberia, Guanacaste (Costa Rica). The experiment design was a randomized unrestricted model; and the CFU was measured before the sowing of the nurseries, along with the dry weight for the calculation of the RGR and CGR at 15, 22 and 29 days after sowing. A lower concentration of CFU of fungi $\left(<10^{4} \mathrm{UFC} / \mathrm{g}\right)$ was observed in the mixtures of $50 \%$ bocashi $+25 \%$ vermicompost $+25 \%$ rice husks; $50 \%$ vermicompost $+25 \%$ sand $+25 \%$ soil and $50 \%$ compost $+25 \%$ bocashi $+25 \%$ coconut fiber (50CBF). The highest dry weight treatment was $50 \%$ bocashi $+25 \%$ compost $+25 \%$ coconut fiber $(50 \mathrm{BCF})$ and $50 \mathrm{CBF}(P<0.01)$. The TCMR in the mixture $50 \%$ bocashi $+25 \%$ sand $+25 \%$ soil was $47 \%$ higher when compared to the control (peat moss); $50 \mathrm{CBF}$ presented the highest CGR. We concluded that the mixtures 50BCF, 50BAS and 50CBF had the best conditions for tomato plants and peat moss (Sphagnum) was among the five least productive mixtures.

Additional key words: horticulture, coconut fiber, bocashi, compost, vermicompost, tomato.

Fecha de recepción: 29-12-2016 Aprobado para publicación: 15-04-2017
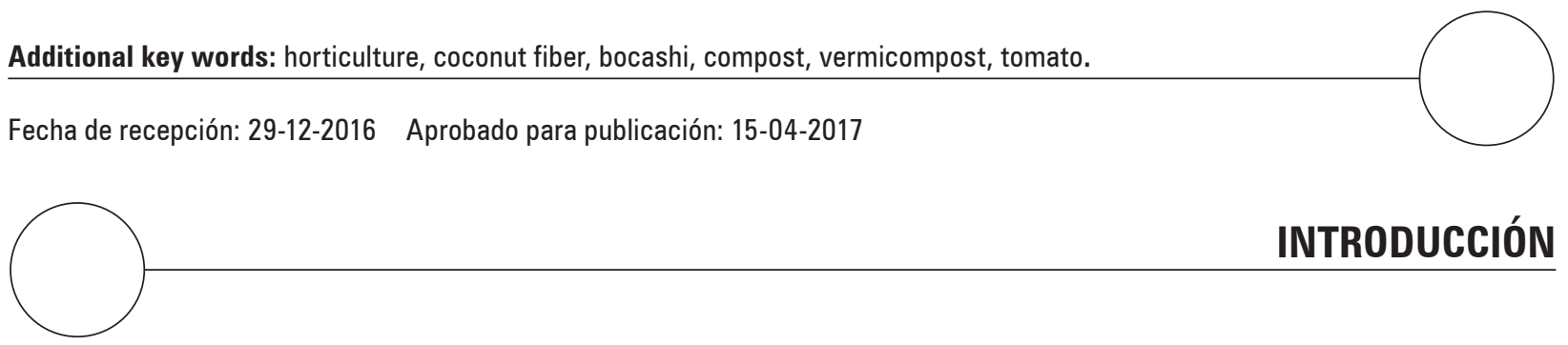

INTRODUCCIÓN

En Costa Rica la producción hortícola es aproximadamente de $186.976 \mathrm{t}$ año-1 (MAG, 2012). Esta actividad genera gran cantidad de empleos e ingresos a más de 12.000 productores, mayoritariamente de la zona central del país (Camacho et al., 2015). Para el 2015 el consumo per cápita de hortalizas en la provincia de Guanacaste alcanzó una demanda de $165 \mathrm{~kg}$, siendo superior al promedio general (156 kg) del país (PIMA, 2015). Esto determinó que el sector es altamente demandante de hortalizas, debido a las personas que viven en la provincia y a la actividad turística temporal. Sin embargo, la zona productora de hortalizas es escasa y se encuentra situada en unos pequeños sectores en las cercanías de los volcanes Rincón de la Vieja, Miravalles, Tenorio, Arenal y en otras pequeñas fincas productoras en la zona de Hojancha. Estas pequeñas unidades de manejo no satisfacen la necesidad existente en la zona, lo que provoca que muchas hortalizas se traigan desde el valle central del país. Además, para que los agricultores de la zona puedan producir hortalizas, también deben de traer los almácigos desde el valle central, haciendo más costoso el proceso productivo.

El uso de almácigos es uno de los principales pilares en la producción hortícola, debido a que garantiza homogeneidad y sanidad en los primeros estados de desarrollo en los cultivos (Quesada y Méndez 2005).
Los almácigos originados bajo condiciones controladas son una herramienta eficiente para la producción de plántulas en la agricultura, puesto que controla las condiciones externas en las etapas más susceptibles de las plantas. Esto evita el desarrollo de fitopatógenos y se favorezcan las condiciones para la germinación. Otro de los factores fundamentales en la producción de almácigos, es el uso de sustratos que se adecuen a las condiciones de un sistema de producción. Los sustratos comerciales a base de turba, son de fácil obtención en países productores del mismo, no obstante, la importación de estos materiales ocasiona que los costos de producción sean elevados. Por esta razón es importante la búsqueda de alternativas para sustituir este material y que sea de fácil obtención para el sistema de producción. Para la elaboración de sustratos se debe tomar en cuenta el costo y preferiblemente que las materias primas sean de la zona (Garbanzo y Navarro, 2015). Además del bajo costo un sustrato debe ser de fácil manejo, ser inerte y proporcionar un bajo impacto ambiental (Tombion et al., 2016).

Las mezclas orgánicas son implementadas en la producción de almácigos o plantas ornamentales, ya que los componentes que aporta cada material establecen un sinergismo mutuo. Es decir, al mezclar vermicompost con granza de arroz, la granza de arroz suministra a la mezcla un mayor espacio poroso, mientras 
que el vermicompost aporta nutrientes esenciales que requieren las plántulas. Las mezclas deben tener suficiente cantidad de componentes orgánicos para acceder cambios importantes en sus propiedades físicas (Arévalo et al., 2016). Se recomienda por lo menos un 40\% de componentes orgánicos para observar beneficios en los sustratos (Quesada y Méndez, 2005). Así mismo, se debe evaluar la calidad de un sustrato en términos de microrganismos benéficos. Estos juegan un papel importante en la sanidad de raíces y por ende la absorción de nutrimentos.

Los microorganismos benéficos son catalogados los componentes más importantes en la degradación y reintegración de materia orgánica al medio, el cual son alternativas para incrementar los rendimientos del cultivo (Bellows et al., 1996; Beltrán-Morales et al., 2016). Los microorganismos constituyen su parte viva y son los responsables de la dinámica de transformación y desarrollo. Se estima que en el caso de los suelos en un solo gramo se pueden encontrar altas concentraciones de microorganismos beneficiosos para los cultivos (Meléndez, 2004; Cisneros et al., 2016).

El uso eficiente de las mezclas, pueden proporcionar un ahorro en relación con los costos de materias primas e insumos nutritivos. Las características ideales para el desarrollo de almácigos, pueden ser representativas con el uso de materias primas de la zona, esto es una alternativa favorable para la diversidad de cultivos y para brindar sostenibilidad agroalimentaria. Dadas las circunstancias, el objetivo de este trabajo fue evaluar algunas características biológicas y químicas en 10 mezclas de sustratos sobre el crecimiento de plántulas de tomate (Solanum lycopersicum L.) en la provincia de Guanacaste, Costa Rica.

\section{MATERIALES Y MÉTODOS}

La investigación se llevó a cabo en el invernadero de la Universidad de Costa Rica, sede de Guanacaste en Liberia, situado geográficamente a $10^{\circ} 36$ '51,97" N y $85^{\circ} 27^{\prime} 31,94^{\prime \prime} \mathrm{W}$, con una altitud de $154 \mathrm{msnm}$. El experimento se desarrolló mediante la selección de mezclas de sustratos durante el periodo de 2011 y 2012 para determinar las mejores 10 mezclas.

Se seleccionó ocho materias primas comunes y utilizadas en la zona, éstas fueros: abonos orgánicos (lombricompost, compost, bocashi), dos subproductos industriales (fibra de coco, granza de arroz), un sustrato comercial (turba), suelo y arena desinfectada. El bocashi fue elaborado previo a la investigación con: granza de arroz, ceniza de granza de arroz, semolina, gallinaza, boñiga, melaza, microorganismos y agua; posteriormente, se mezcló diariamente durante $22 \mathrm{~d}$ hasta que la temperatura se estabilizara. Las mezclas se elaboraron de acuerdo a las proporciones establecidas; en los tratamientos de bocashi, compost y lombricompost se usó una proporción del $50 \%$ de base y se mezcló en una proporción de $25 \%$ alguno de los siguientes productos: arena, suelo, fibra de coco y granza de arroz (Tab. 1).

El ensayo se realizó en bandejas plásticas de 72 celdas, en forma de pirámide invertida. El sustrato se humedeció y se procedió a llenar las bandejas. Se llenaron las 48 celdas centrales y se evaluaron cuatro bandejas por tratamiento. La planta indicadora usada fue tomate (S. lycopersicum) de la variedad Hayslip y las semillas se sembraron a $0,25 \mathrm{~cm}$ de profundidad. El riego por microaspersión se aplicó una vez al día, durante 15 min. Se estimó que en cada celda se suministraba 4,40 $\mathrm{mL}$ diarios. Durante el desarrollo del experimento no se suministró ningún insumo (fungicida, insecticida y fertilizante) a los almácigos.

\begin{tabular}{|c|c|c|c|}
\hline Mezclas & Asignatura & Tratamientos & Proporción \\
\hline 1 & $50 B L G$ & $50 \% B+25 \% L+25 \% G$ & $2: 1: 1$ \\
\hline 2 & 50BCF & $50 \% B+25 \% C+25 \% F$ & $2: 1: 1$ \\
\hline 3 & 50BAS & $50 \% B+25 \% A+25 \% S$ & $2: 1: 1$ \\
\hline 4 & $50 \mathrm{LBG}$ & $50 \% L+25 \% B+25 \% G$ & $2: 1: 1$ \\
\hline 5 & $50 \mathrm{LCF}$ & $50 \% L+25 \% C+25 \% F$ & $2: 1: 1$ \\
\hline 6 & 50LAS & $50 \% L+25 \% A+25 \% S$ & $2: 1: 1$ \\
\hline 7 & $50 C L G$ & $50 \% C+25 \% L+25 \% G$ & $2: 1: 1$ \\
\hline 8 & $50 \mathrm{CBF}$ & $50 \% C+25 \% B+25 \% F$ & $2: 1: 1$ \\
\hline 9 & 50CAS & $50 \% C+25 \% A+25 \% S$ & $2: 1: 1$ \\
\hline 10 & 100PM & 100\% PM (testigo) & 1 \\
\hline
\end{tabular}

A: arena; B: bocashi; C: compost; F: fibra de coco; G: granza; L: lombricompost; PM: peat moss; S: suelo solarizado.

\section{Variables evaluadas}

Se evaluaron variables químicas de los sustratos, donde se midió el $\mathrm{pH}$ en agua, conductividad eléctrica, $\mathrm{N}-\mathrm{NH}_{4}{ }^{+}$y $\mathrm{N}_{-} \mathrm{NO}_{3}{ }^{-}$mediante la extracción por pasta saturada y análisis de agua. En la parte microbiológica se midió la concentración total de unidades 
formadoras de colonias (UFC/g) de hongos, actinomicetos y bacterias totales. Todas las muestras fueron analizadas en el Laboratorio de Suelos, Foliares y Microbiología Agrícola del Centro de Investigaciones Agronómicas (CIA) de la Universidad de Costa Rica.

Se cosecharon cinco plantas por cada repetición para una muestra de 20 plantas por tratamiento. Las variables evaluadas fueron:

Porcentaje de germinación. En cada celda se determinó la cantidad de semillas que germinaron a los 7, 8, 10 y 11 dds. Se realizó una prueba de germinación en una cámara para este fin, donde se colocaron 100 semillas de tomate en platos Petri con el fin de cuantificar el porcentaje real de germinación de las semillas utilizadas.

Peso seco de tallo. Consistió en cortar la parte aérea de la planta (incluyendo hojas) y se colocó en un horno a $75^{\circ} \mathrm{C}$ durante $72 \mathrm{~h}$, luego se pesó en una balanza analítica. Se evaluaron a los 15, 22 y 29 dds.

Peso seco de raíz. Se seccionaron las raíces y se colocaron en un horno durante $72 \mathrm{~h} \mathrm{a} 75^{\circ} \mathrm{C}$, posteriormente se procedió a pesar en balanzas analíticas. Se evaluaron a los 15,22 y 29 dds.

Grosor de tallo. Consistió en medir con un vernier el grosor $(\mathrm{cm})$ de la parte inferior del tallo a $0,5 \mathrm{~cm}$ de la base del sustrato. Este dato se evaluó a los 29 dds.

Número de hojas. Se realizó un conteo de las hojas verdaderas presentes en cinco plántulas por unidad experimental. Este dato se evaluó a los 29 dds.

Unidades Spad. Se utilizó un SPAD 502 plus, donde se determinó un índice de coloración en las hojas. Se midió en 10 plantas por repetición en cada tratamiento y se evaluó a los 29 dds.

Análisis de crecimiento. Se sumaron los pesos secos de raíz y tallo. Se calculó: tasa de crecimiento relativo (TCR) y la tasa de crecimiento de cultivo (TCC); según las fórmulas de Rodríguez y Leihner (2006).

Temperatura de los sustratos. se midió con termómetros graduados de $100^{\circ} \mathrm{C}$, se introdujeron los termómetros dentro del sustrato, estimando que la superficie de mercurio estuviera expuesta en el centro de la celda. Posteriormente se midió cada media hora la temperatura de cada termómetro de 6:30 am a 5:30 pm. La temperatura se medió dos veces por semana.
Los termómetros se rotaron en las cuatro mesas durante el ensayo.

\section{Diseño experimental}

Se colocaron cuatro mesas en el invernadero, cada una de estas representó un bloque; los 10 tratamientos se distribuyeron en forma aleatoria en cada bloque (4 bloques, 10 tratamientos) para un total de 40 bandejas. El diseño experimental fue un modelo irrestricto al azar. Para el análisis de los datos, se usó el índice de área bajo la curva para determinar separaciones entre medias (Ecuac. 1). El experimento se analizó con diferencias mínimas significativas $(\alpha=0,01)$ para las variables paramétricas y prueba de Kruskal Wallis $(\alpha=0,05)$ para las no paramétricas.

$$
\sum \frac{b+B \times a}{2}
$$

Donde:

b: medida en el tiempo 2 (T1).

B: medida en el tiempo 1 (T2).

a: número de días trascurridos entre T1 y T2.

\section{RESULTADOS Y DISCUSIÓN}

\section{Variables microbiológicas de las mezclas de sustratos}

La menor concentración de hongos $\left(<10^{4} \mathrm{UFC} / \mathrm{g}\right)$ se encontró en las mezclas 50BLG, 50LAS, 50CBF, mientras que las UFC de bacterias se presentaron en menor cantidad ( $<10^{6} \mathrm{UFC} / \mathrm{g}$ ) en los tratamientos 50BLG, 50CBF, 50CLG y 50LAS (Tab. 1). La concentración de hongos y bacterias posiblemente fue determinada por las materias primas y el grado de estructura que presentó cada mezcla. La fibra de coco y la granza, son componentes con altos contenidos de lignina y fibra, el cual los convierte en un sustrato ideal para el desarrollo de los hongos (Valverde et al., 2007; Tombion et al., 2016).

Los hongos son los primeros en actuar en la descomposición de la materia orgánica (Cisneros et al., 2016), por esta razón, la mayor concentración de hongos ( $\left.>10^{5} \mathrm{UFC} / \mathrm{g}\right)$, se encontró en los materiales que tenían estados intermedios de descomposición (Álvarez, 2005; Arévalo et al., 2016). El compost que 
Tabla 2. Unidades formadoras de colonias de hongos, bacterias y actinomicetos totales en 10 mezclas de sustratos antes de la siembra de los almácigos.

\begin{tabular}{|c|c|c|c|}
\hline Mezclas & Hongos (UFC/g) & Bacterias (UFC/g) & Actinomicetos (UFC/g) \\
\hline $50 B L G$ & $2,0 \times 10^{3}$ & $2,0 \times 10^{5}$ & $<10^{4}$ \\
\hline $50 B C F$ & $1,0 \times 10^{5}$ & $1,0 \times 10^{6}$ & $2,0 \times 10^{5}$ \\
\hline $50 B A S$ & $5,0 \times 10^{4}$ & $6,0 \times 10^{6}$ & $<10^{4}$ \\
\hline $50 L B G$ & $8,0 \times 10^{4}$ & $2,0 \times 10^{6}$ & $5,0 \times 10^{5}$ \\
\hline $50 L C F$ & $5,0 \times 10^{4}$ & $4,0 \times 10^{6}$ & $<10^{4}$ \\
\hline $50 L A S$ & $4,0 \times 10^{3}$ & $6,0 \times 10^{5}$ & $<10^{4}$ \\
\hline $50 C L G$ & $1,5 \times 10^{5}$ & $5,0 \times 10^{5}$ & $<10^{4}$ \\
\hline $50 C B F$ & $6,0 \times 10^{3}$ & $2,0 \times 10^{5}$ & $1,0 \times 10^{5}$ \\
\hline $50 C A S$ & $1,2 \times 10^{5}$ & $4,2 \times 10^{6}$ & $5,0 \times 10^{5}$ \\
\hline
\end{tabular}

A: arena; B: bocashi; C: compost; F: fibra de coco; G: granza; L: lombricompost; PM: peat moss; S: suelo solarizado.

se utilizó fue una mezcla de un $50 \%$ de compost a base de boñiga y un $50 \%$ compost a base de residuos de plantas de piña. Este último material posee altas cantidades de lignina, lo que explica la presencia de hongos en las mezclas.

El lombricompost se degrada en el sistema digestivo de la lombriz, indicando que posiblemente las concentraciones de bacterias sean altas $\left(>10^{6} \mathrm{UFC} / \mathrm{g}\right)$ en los sustratos con presencia del material. Las bacterias prefieren los materiales con niveles altos de degradación, debido a que poseen partículas más pequeñas y las enzimas pueden degradar los materiales con mayor facilidad (Rosemeyer et al., 2000, Álvarez, 2005). Esto coincide con lo reportado por Durán y Henríquez (2007), quienes encontraron concentraciones altas ( $>10^{6} \mathrm{UFC} / \mathrm{g}$ ) de bacterias en vermicompost de distintas fuentes primarias.

Se encontró que las mezclas 50LCF, 50BAS, 50CAS y 100PM fueron los que presentaron concentraciones más altas de actinomicetos entre los tratamientos. Los demás tratamientos, presentaron concentraciones menores a $10^{4}$, lo que se consideran UFC bajas (Tab. 2). Los actinomicetos son los responsables de la generación de temperatura en la descomposición de materia orgánica (Pérez-Rojas et al., 2015). Las concentraciones de actinomicetos predicen la madurez de un sustrato, por lo que podría establecer que a menor concentración de UFC $\left(<10^{5} / \mathrm{g}\right)$ de actinomicetos, los materiales se encuentran en etapas avanzadas de descomposición, mientras que a altas UFC $\left(>10^{5} / \mathrm{g}\right)$ los materiales se encuentran en descomposición activa. La mayoría de los sustratos mostraron concentraciones menores a $10^{5} \mathrm{UFC} / \mathrm{g}$, indicando que los materiales orgánicos utilizados en la preparación de las mezclas, tienen etapas avanzadas de descomposición o bien una inactividad de los microrganismos, lo cual presentó una temperatura estable. Es importante que los sustratos muestren una estabilidad en el tiempo con el fin de que no cambie sus características fisicoquímicas rápidamente, la estabilización de los microorganismos y la temperatura determinan que la degradación de los materiales en este ensayo probablemente se detuvo, sin embargo, para futuros trabajos sería deseable evaluar la actividad microbiana en el tiempo.

\section{Germinación S. lycopersicum en las 10 mezclas de sustratos}

Al evaluar el porcentaje de la semilla de tomate en una cámara de germinación, se encontró alta viabilidad de las semillas, el cual tuvo un $92 \%$ de germinación. Al analizar la germinación bajo la influencia de las distintas mezclas de sustratos, se encontró que el porcentaje de germinación a los 7 dds fue un $86 \%$ para 50CAS, $85 \%$ en 50LCF y $81 \%$ en 50LAS respectivamente, siento más alto que el resto de los tratamientos (Fig. 1). Posterior a los 10 dds la germinación en estos tratamientos fueron superiores al $90 \%$. Las mezclas que mostraron la menor germinación fueron: $50 \mathrm{BLG}$ con un $7 \%, 50 \mathrm{BCF}$ con un $23 \%$ y $50 \mathrm{BAS}$ con un $26 \%$. Todas las mezclas con una base de $50 \%$ bocashi mostraron problemas en la germinación y éste disminuyó hasta un 20\% comparando a las demás mezclas. 


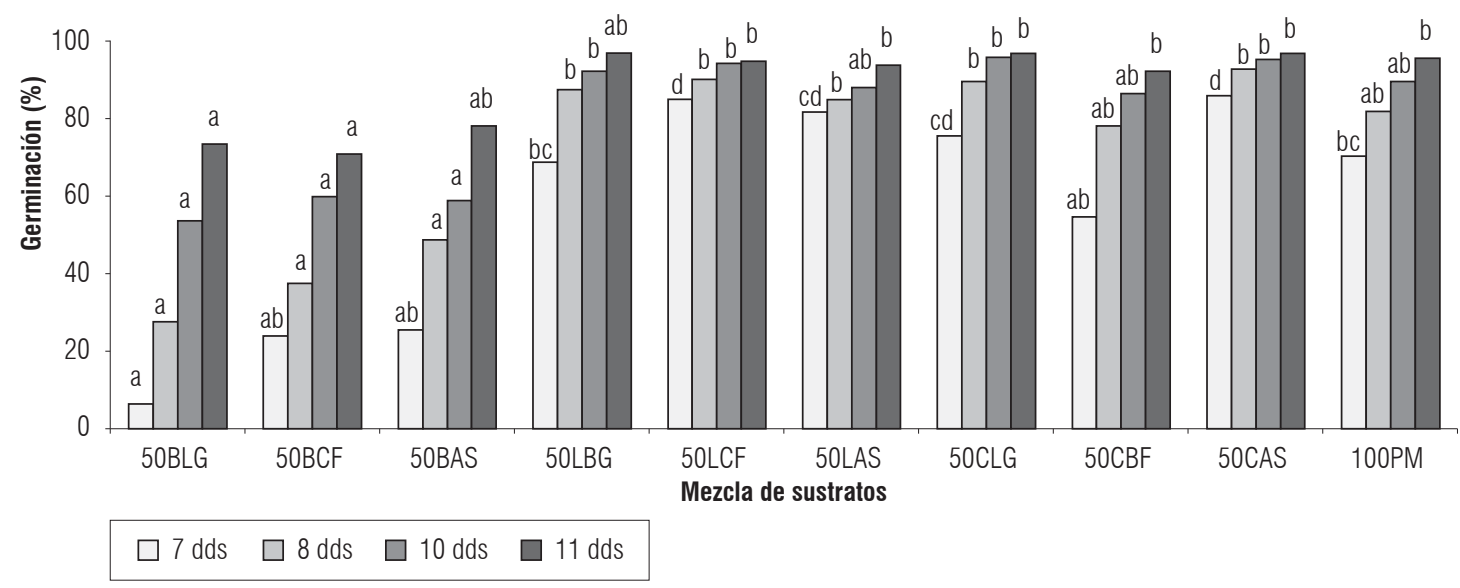

Figura 1. Porcentaje de germinación evaluada a los 7, 8, 10 y 11 dds en $S$. lycopersicum sembrado en 10 mezclas de sustratos para la producción de almácigos. A: arena; B: bocashi; C: compost; F: fibra de coco; G: granza; L: lombricompost; PM: peat moss; S: suelo solarizado.

Es probable que el efecto de la pobre germinación en las mezclas con una base de 50 de bocashi sea producto de una reactivación microbiana. Es decir, el bocashi detiene su proceso de descomposición al agotar el agua disponible en su elaboración, lo cual detiene la actividad microbiana. Al agregar agua al bocashi, se reanuda la etapa de crecimiento logarítmico y este vuelve lentamente a aumentar su actividad microbiana, lo cual hace que comience la descomposición nuevamente y por ende presente un aumento de la temperatura en el sustrato (Fig. 4). Es probable que este aumento de la temperatura influya negativamente en la germinación de las semillas. El aumento de temperatura registrados en bocashi pueden llegar a más de $70^{\circ} \mathrm{C}$ (Restrepo, 2001). El efecto de la temperatura tiene una relación directa en la velocidad de germinación en las semillas, sin embargo, a temperaturas altas o bajas pueden propiciar una disminución en la velocidad de la germinación o bien disminuir su viabilidad (Herrera et al., 2006). El incremento de la temperatura provoca un aumento en la intensidad de las reacciones metabólicas y disminuye la solubilidad de oxígeno en el agua de imbibición, lo que disminuye la cantidad de oxigeno que requiere el embrión (Herrera et al. 2006). Además, al ser la bioactivación un proceso aeróbico también influye en la cantidad de oxígeno disuelto en el sustrato. Así mismo, las mezclas que disminuyeron el porcentaje de germinación (50BLG, 50BCF, 50BAS) presentaron temperaturas de los sustratos mayores a $33,6^{\circ} \mathrm{C}$. Las mezclas con mayor porcentaje de germinación (50LBG, 50LCF, 50LAS, 50CLG, 50CAS, 100PM) mostraron temperaturas menores a $33,3^{\circ} \mathrm{C}$.
$\mathrm{Al}$ analizar el comportamiento de las temperaturas de los sustratos en la primera semana de producción, probablemente influyeron en la germinación de las semillas (Fig. 2). Posiblemente otro factor que influyó en la germinación, fue por la captación de energía, producto de la radiación en el sustrato y su relación con el color de las mezclas con Bocashi. Los sustratos más oscuros pudieron aumentar su calor especifico, al retener mayor radiación similar a lo que ocurre en los primeros centímetros de profundidad del suelo. Investigaciones desarrolladas por Llorente (2002) indicaron que el calentamiento del suelo dependerá de la radiación neta y el color presente, ya que, suelos con presencia de materia orgánica (oscuros) adsorben mayor radiación que suelos sin presencia de éste, aumentando la temperatura gradualmente. Sin embargo, Jury et al. (1991) encontraron que los sustratos húmedos se calientan más lentamente que los secos, pero pueden mantener más el calor reduciendo las variaciones de temperatura.

Otro factor que probablemente afectó la germinación de las semillas fueron las concentraciones salinas de los sustratos (Tab. 3). Al analizar las concentraciones de sales, se encontró que la mayoría de los tratamientos poseen niveles de conductividad eléctrica (CE) superiores a $3,5 \mathrm{dS} \mathrm{m}^{-1}$; los rangos específicos para bocashi están entre 7,8 y 10,8 dS $\mathrm{m}^{-1}$. Esto concuerda con la germinación heterogénea en los primeros 9 dds, sin embargo, la germinación aumentó a los 11 dds, lo cual explicaría que conforme se suministró el riego, es probable que las sales se lavaron con el tiempo. La CE superior a $3,5 \mathrm{dS} \mathrm{m}^{-1}$ es problemática para 


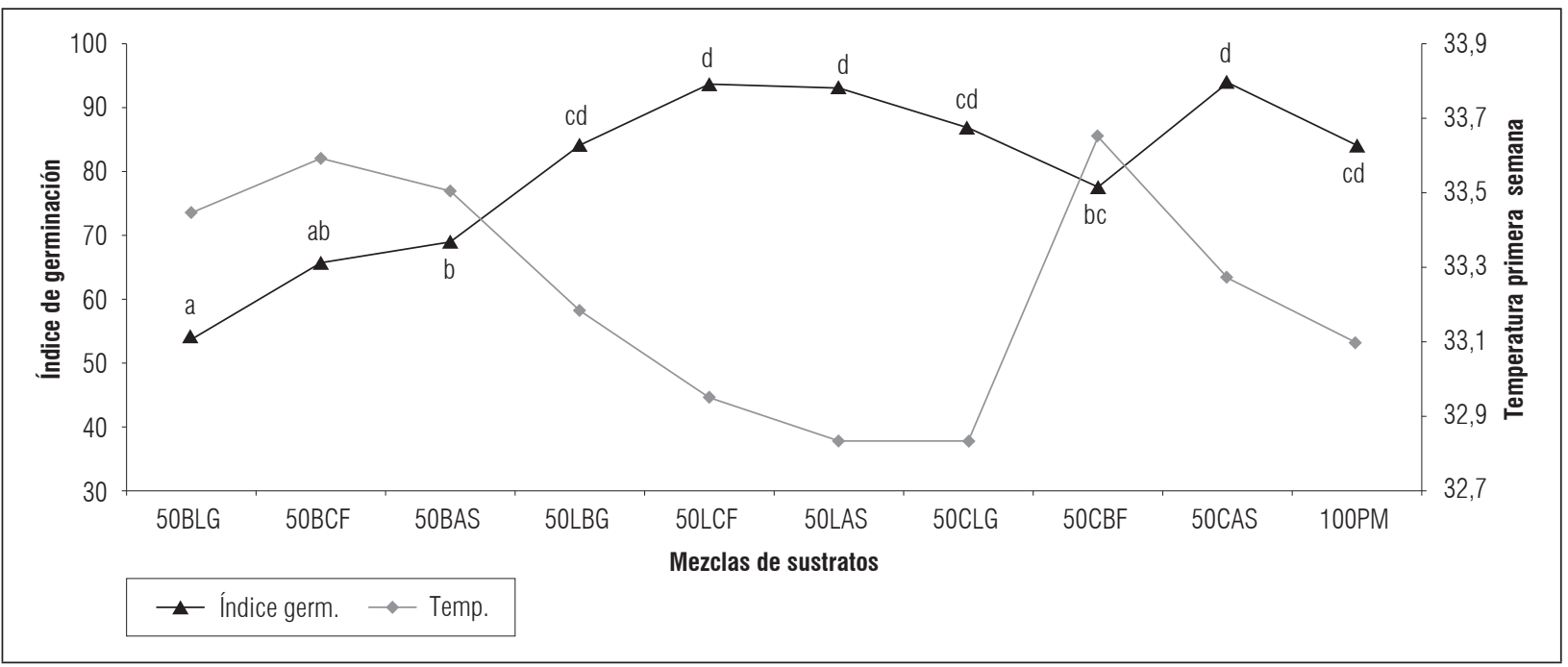

Figura 2. Relación entre el índice de área bajo la curva (abc) de la germinación y las temperaturas internas de las mezclas de sustratos en la primera semana de evaluación (1-10 dds). A: arena; B: bocashi; C: compost; F: fibra de coco; G: granza; L: lombricompost; PM: peat moss; S: suelo solarizado.

el crecimiento de las plántulas (Azcón-Bieto y Talón, 2003; Lesmes et al., 2007). Las sales pueden propiciar un mayor efecto osmótico en los sustratos comparado con la presión osmótica generada dentro de la semilla, lo que imposibilitaría una adecuada imbibición en el proceso de germinación.

\section{Tabla 3. Contenido de nutrimentos antes de la siembra de los almácigos en 10 mezclas de sustratos, mediante la metodología de pasta saturada.}

\begin{tabular}{|c|c|c|c|c|}
\hline Mezclas & $\mathrm{pH}$ & $\mathrm{N}-\mathrm{NH}_{4}{ }^{+}$ & $\mathrm{N}-\mathrm{NO}_{3}{ }^{-}$ & CE \\
\hline - & - & \multicolumn{2}{|c|}{ mg L-1 ---- } & $\mathrm{dS} \mathrm{m}^{-1}$ \\
\hline Óptimos & $5,3-6,5$ & $0-20$ & $80-200$ & $1,2-3,5$ \\
\hline 50BLG & 6,3 & 212,7 & 2,8 & 10,8 \\
\hline $50 \mathrm{BCF}$ & 6,5 & 211,1 & 2,1 & 7,2 \\
\hline 50BAS & 6,5 & 370,1 & 2,6 & 7,8 \\
\hline 50LBG & 7,2 & 130,5 & 0,9 & 5,2 \\
\hline 50LCF & 6,9 & 1,4 & 363,9 & 5,7 \\
\hline 50LAS & 7,5 & ND & 621,1 & 5,8 \\
\hline 50CLG & 6,9 & 25,3 & 177,8 & 4,0 \\
\hline $50 \mathrm{CBF}$ & 6,8 & 135,0 & 0,1 & 6,1 \\
\hline 50CAS & 6,5 & 23,7 & 359,8 & 3,1 \\
\hline $100 \mathrm{PM}$ & 6,0 & 1,5 & 1,1 & 1,3 \\
\hline
\end{tabular}

CE: conductividad eléctrica; A: arena; B: bocashi; C: compost; F: fibra de coco; G: granza; L: Iombricompost; PM: peat moss; S: suelo solarizado.

\section{Crecimiento en las plántulas de tomate}

Los tratamientos que presentaron los pesos secos de tallo más altos fueron: $50 \mathrm{BCF}$ con un $73 \%$ de mayor peso al testigo (100PM), 50CBF con un $71 \%$ y $50 \mathrm{LBG}$ con un $59 \%$. El tratamiento que presentó el peso seco de tallo más bajo fue el tratamiento testigo (Tab. 4). Los demás tratamientos no mostraron diferencias mínimas significativas. El tratamiento que presentó el mayor peso seco en la raíz, fue la mezcla 50LBG que superó en un $54 \%$ del peso al tratamiento testigo (100PM), mientras que Díaz et al. (2010) encontraron que el sustrato puro de fibra de coco de Brasil desarrolló el mayor peso seco de raíces en uchuva (Physalis peruviana L.). El resto de los tratamientos no presentaron diferencias estadísticamente significativas.

El grosor de tallo en el tratamiento 50LBG mostró un $42 \%$ más que el tratamiento testigo (100PM), siendo el tratamiento testigo el que presentó un menor grosor. Los demás tratamientos no mostraron diferencias estadísticamente significativas. Además, los tratamientos que presentaron el mayor número de hojas (>3) fueron las mezclas 50BLG, 50BCF, 50BAS, 50LBG, 50LAS y 50CBF, mientras que los tratamientos 50CAS, 50CLG y 50LCF presentaron el menor número, así mismo el tratamiento 100PM presentó el menor número de hojas; esto se atribuye a la concentración de $\mathrm{N}$ que aportaron los sustratos orgánicos, lo cual fue muy bajo para el peat moss. 
Tabla 4. Influencia de las mezclas de sustratos en el crecimiento de plántulas de tomate sembrada en almácigos.

\begin{tabular}{|c|c|c|c|c|c|c|c|}
\hline Mezclas & PS tallo $(\mathrm{g})$ & PS raíz $(\mathrm{g})$ & $\begin{array}{c}\text { Grosor tallo } \\
(\mathrm{cm})\end{array}$ & No. hojas & $\begin{array}{c}\text { TCC } \\
\left(\mathrm{g} \mathrm{m}^{-2} \mathrm{~d}^{-1}\right)\end{array}$ & $\begin{array}{c}\text { TCR } \\
\left(\mathrm{g} \mathrm{g}^{-1} \mathrm{~d}^{-1}\right)\end{array}$ & $\begin{array}{c}\text { Coloración } \\
(\text { Un. Spad) }\end{array}$ \\
\hline 50BLG & $0,61 \mathrm{ab}$ & $0,09 \mathrm{abc}$ & $0,25 \mathrm{bcd}$ & $3,2 \mathrm{~b}$ & $6,16 \mathrm{~b}$ & $0,20 \mathrm{ab}$ & 24,8 \\
\hline 50BCF & $1,16 \mathrm{~b}$ & $0,10 \mathrm{~cd}$ & $0,27 \mathrm{bcd}$ & $3,4 \mathrm{~b}$ & $6,20 \mathrm{~b}$ & $0,17 \mathrm{ab}$ & 25,7 \\
\hline 50BAS & $0,79 \mathrm{ab}$ & $0,09 \mathrm{abc}$ & $0,25 \mathrm{bcd}$ & $3,4 \mathrm{~b}$ & $8,00 \mathrm{ab}$ & $0,21 \mathrm{a}$ & 25,8 \\
\hline 50LBG & $0,99 \mathrm{~b}$ & $0,13 \mathrm{~d}$ & $0,31 \mathrm{~d}$ & $3,4 \mathrm{~b}$ & $9,51 \mathrm{ab}$ & $0,20 \mathrm{ab}$ & 25,4 \\
\hline 50LCF & $0,57 \mathrm{ab}$ & $0,06 \mathrm{ab}$ & $0,22 \mathrm{ab}$ & $2,8 \mathrm{ab}$ & $3,08 \mathrm{~b}$ & $0,13 \mathrm{ab}$ & 24,7 \\
\hline 50LAS & $0,85 \mathrm{ab}$ & $0,10 \mathrm{~cd}$ & $0,25 \mathrm{bcd}$ & $3,1 \mathrm{~b}$ & $6,22 \mathrm{ab}$ & $0,15 \mathrm{ab}$ & 26,3 \\
\hline 50CLG & $0,61 \mathrm{ab}$ & $0,08 \mathrm{abc}$ & $0,24 \mathrm{abc}$ & $2,6 \mathrm{ab}$ & $5,01 \mathrm{ab}$ & $0,15 \mathrm{ab}$ & 25,2 \\
\hline 50CBF & $1,13 \mathrm{~b}$ & $0,12 \mathrm{~cd}$ & $0,3 \mathrm{~cd}$ & $3,6 \mathrm{~b}$ & $10,87 \mathrm{a}$ & $0,20 \mathrm{ab}$ & 25,3 \\
\hline 50CAS & $0,87 \mathrm{ab}$ & $0,09 \mathrm{~cd}$ & $0,24 \mathrm{abc}$ & $2,8 \mathrm{ab}$ & $6,29 \mathrm{ab}$ & $0,15 \mathrm{ab}$ & 27,5 \\
\hline 100PM & $0,31 \mathrm{a}$ & $0,06 \mathrm{a}$ & $0,18 \mathrm{a}$ & $2,0 \mathrm{a}$ & $1,95 \mathrm{~b}$ & $0,11 \mathrm{~b}$ & 24,7 \\
\hline Valor $P$ & 0,01 & $<0,01$ & $<0,01$ & $<0,01$ & $<0,01$ & 0,03 & 0,64 \\
\hline DMS & 0,61 & 0,03 & 0,06 & 0,9 & 4,65 & 0,09 & - \\
\hline
\end{tabular}

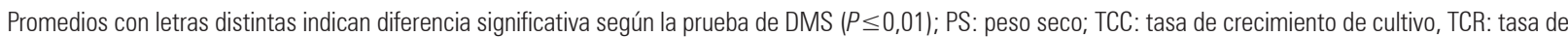
crecimiento relativo; coloración: unidades Spad, analizado con pruebas de Kruskal Wallis $(\alpha=0,05)$. A: arena; B: bocashi; C: compost; F: fibra de coco; G: granza; L: lombricompost; PM: peat moss; S: suelo solarizado.

Las mezclas con sustratos orgánicos presentaron mayor crecimiento y desarrollo de plántulas que el peat moss. Richmond (2010) encontró que al agregar abono orgánico a las mezclas de sustratos, mejoró el crecimiento de las plántulas de tomate. El abono orgánico presenta múltiples cargas negativas en su estructura amorfa, lo cual permite que muchos de los cationes se adhieran a la superficie permitiendo retener nutrimentos que son liberados durante el proceso de mineralización en la descomposición del material orgánico. Los abonos orgánicos poseen mayores contenidos de nutrimentos, lo que hace que las plántulas puedan absorberlos durante su crecimiento. Lo anterior explicaría el efecto del tratamiento peat moss, que presentó el menor contenido nutricional y el menor crecimiento en comparación con los demás tratamientos.

La coloración de las hojas en las plántulas de tomate determinados en unidades Spad, no presentaron diferencias estadísticas (Tab. 4). Los índices Spad en los tratamientos 50LBG y 100PM mostraron un contenido de 24,7 de unidades, mientras que el tratamiento 50CAS mostró un contenido de 27,5. Las unidades Spad son correlacionados con los contenidos de nitrógeno y de clorofila que tienen las plantas, lo cual brindaría una idea de los contenidos nutricionales, principalmente de $\mathrm{N}$ que posee las hojas en un preciso momento (Villalobos, 2001; Azcón-Bieto y Talón, 2003). Los contenidos de $\mathrm{NH}_{4}^{+}$y N-NO${ }_{3}^{-}$fueron altos
(>20; > $200 \mathrm{mg} \mathrm{L}^{-1}$ ) en la mayoría de los tratamientos (Tab. 3); ambos contenidos no se reflejaron significativamente con las unidades Spad. Rodríguez et al. (1998), encontraron que el contenido de clorofila en las plantas de tomate medidos con Spad, presentaron las mayores unidades $(56,11)$ a los $45 \mathrm{~d}$ después del trasplante y estas plantas ya poseían fertilizaciones nitrogenadas. Los contenidos $(24,7-25,5)$ encontrados en las plántulas a los $29 \mathrm{dds}$, probablemente sean bajos debido a que los almácigos no presentaron fertilizaciones nitrogenadas y que se encuentran en etapas activas de crecimiento.

La tasa de crecimiento relativo (TCR) en la 50BAS fue un $47 \%$ más alta al compararlas al testigo (100PM), sin embargo, los demás tratamientos no presentaron diferencias significativas (Tab. 4). Las mezclas que presentaron las plántulas con la menor TCC fueron 100PM (testigo), 50LCF, 50CLG, 50BLG y 50BCF, mientras que la mezcla $50 \mathrm{CBF}$ presentó la mayor TCC, significativamente. Los demás tratamientos no mostraron diferencias significativas entre sí. Las TCC indicaron la eficiencia de crecimiento de biomasa por celda, mostrando la ganancia de materia seca aportada por las características atribuidas en cada mezcla. Posiblemente este índice en almácigos sea de crecimiento exponencial, ya que decae hasta llegar a la etapa de máximo crecimiento, o bien, a senescencia en los cultivos (Barraza et al., 2004; Rodríguez y Leihner, 2006). 


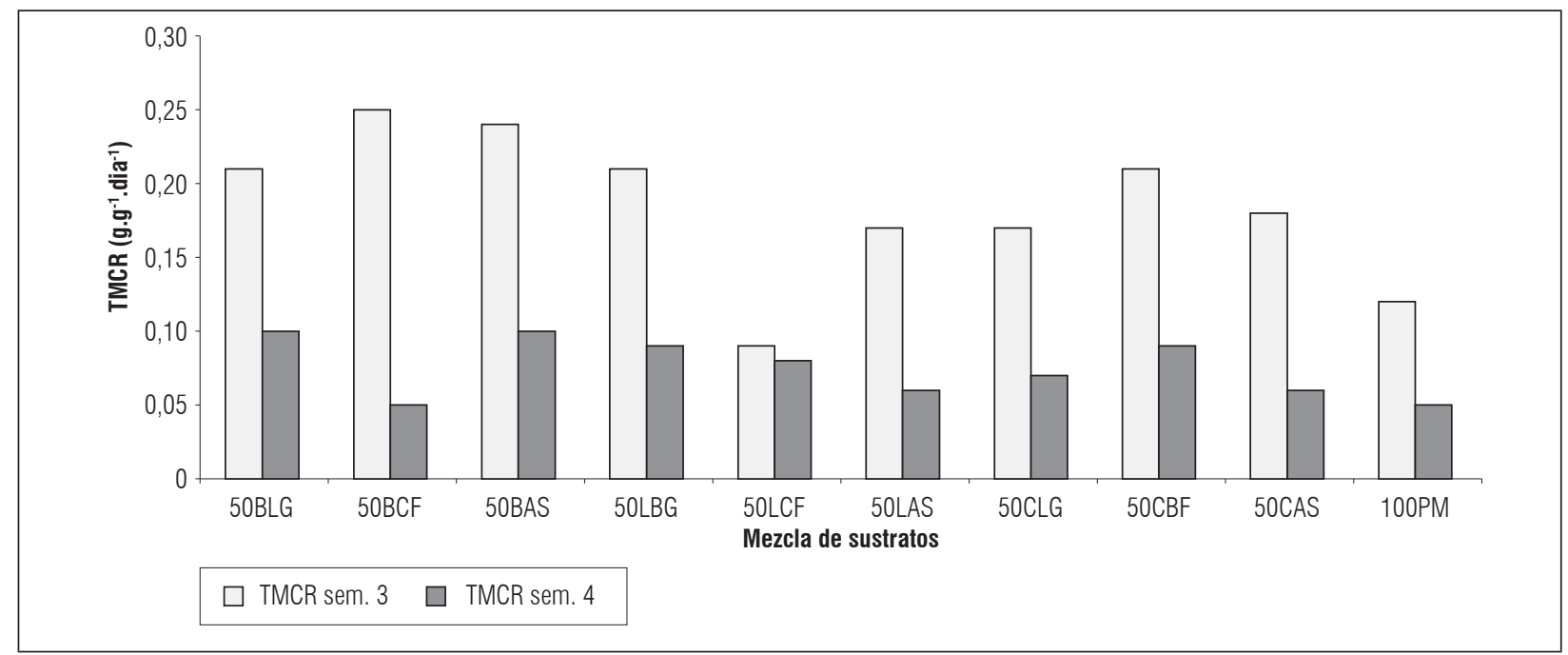

Figura 3. Tasa de crecimiento relativo (TCR) de plántulas de tomate sembradas en 10 mezclas de sustratos. Barras de color oscuro cuantifica la TCR hasta la semana 3 y barras claras cuantifican la TCR en la semana 4 después de la siembra. A: arena; B: bocashi; C: compost; F: fibra de coco; G: granza; L: lombricompost; PM: peat moss; S: suelo solarizado.

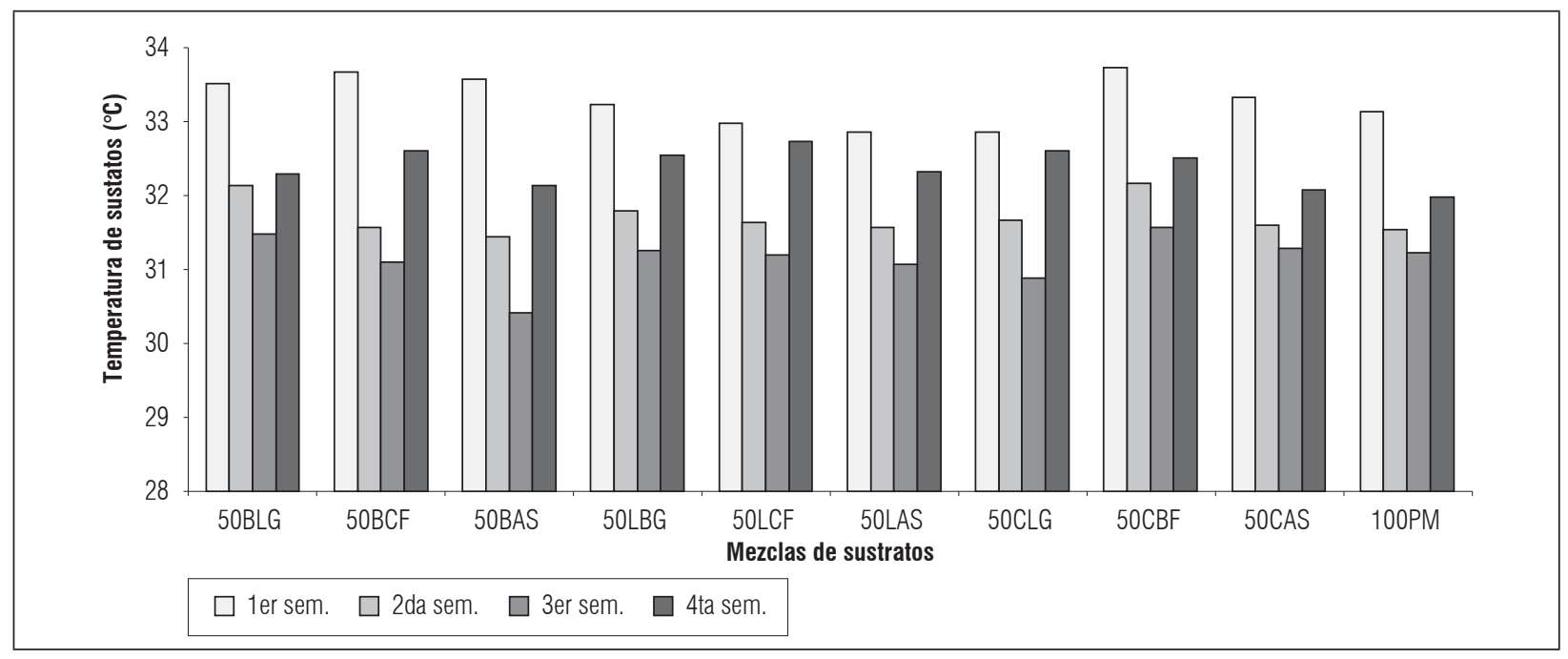

Figura 4. Promedio de las temperaturas en las mezclas de los sustratos por semana. A: arena; B: bocashi; C: compost; F: fibra de coco; G: granza; L: lombricompost; PM: peat moss; S: suelo solarizado.

La mayoría de las mezclas de sustratos presentaron una TMCR mayor en la semana 3 que en la semana 4 (Fig. 3). La TMCR mostró el índice de la eficiencia de la planta para producir materia seca (Rodríguez y Leihner, 2006), se encontró que todos los tratamientos excepto el peat moss, mostraron una tasa de acumulación de materia seca para plántulas de tomate entre 0,13 y $0,21 \mathrm{~g} \mathrm{~g}^{-1} \mathrm{~d}^{-1}$ en los días 15 a $29 \mathrm{dds}$. Sin embargo, esta tasa fue más eficiente en la tercera semana, ya que acumuló un promedio de $0,18 \mathrm{~g} \mathrm{~g}^{-1} \mathrm{~d}^{-1}$ en comparación a la semana 4 que acumuló $0,07 \mathrm{~g}$ $\mathrm{g}^{-1} \mathrm{~d}^{-1}$. La disminución del crecimiento en la semana 4, posiblemente fue causado por dos limitantes: la expansión de las raíces producto del volumen de la celda y un ligero aumento en la temperatura de la semana 3 a la 4 (Fig. 4). Esto coincide con Rodríguez y Leihner (2006) y Azcón-Bieto y Talón (2003), quienes determinaron que el cambio de temperatura, los contenidos nutricionales y propiedades físicos de los suelos, son factores externos que afectan la TCR. Por 
lo tanto, la tercera semana ( 22 dds) es la semana óptima para realizar el trasplante, lo que reduciría en 8 d el momento de la siembra.

\section{CONCLUSIONES}

Las mezclas que presentaron las mejores condiciones químicas, biológicas y de crecimiento en tomate para producción de almácigos en Guanacaste, fueron las mezclas: $50 \%$ lombricompost $+25 \%$ bocashi $+25 \%$ granza; $50 \%$ bocashi $+25 \%$ compost $+25 \%$ fibra de coco y $50 \%$ compost $+25 \%$ bocashi $+25 \%$ fibra de coco. Por otra parte, es importante planificar los trasplantes para este cultivo a los $22 \mathrm{dds}$, debido a que las condiciones de temperatura en los invernaderos aceleran el crecimiento de la plántula de tomate en Guanacaste.

\section{REFERENCIAS BIBLIOGRÁFICAS}

Álvarez, S. 2005. La descomposición de la materia orgánica en humedales: la importancia del componente microbiano. Rev. Ecosist. 14(2), 17-29.

Arévalo, M., C. Oberpaur y C. Méndez. 2016. Inclusión de musgo (Sphanum magellanicum Brid) y fibra de coco como componentes orgánicos del sustrato para almácigos de kiwi (Actinidia deliciosa). Rev. Indesia 34(2), 47-55. Doi: 10.4067/S0718-34292016005000007

Azcón-Bieto, J. y M. Talón. 2003. Fundamentos de fisiología vegetal. $3^{\text {er }}$ ed. McGraw-Hill Interamericana, Madrid, España.

Barraza, F., G. Fischer y C. Cardona. 2004. Estudio del proceso de crecimiento del cultivo de tomate (Lycopersicon esculentum Mill.) en el Valle del Sinú medio, Colombia. Agron. Colomb. 22(1), 81-90,

Bellows, B.C., P.E. Hildebrand y D.H. Hubbell. 1996. Sustainability of bean production systems on steep lands in Costa Rica. Agric. Syst. 50(4), 391-410. Doi: 10.1016/0308-521X(94)00069-4

Beltrán-Morales, F., J. García-Hernández, F. Ruiz-Espinoza, R. Valdez-Cepeda, P. Preciado-Rangel, M. Fortis-Hernández y A. González-Zamora. 2016. Efecto de sustratos orgánicos en el crecimiento de seis variedades de chile jalapeño (Capsicum annuum L.). Ecosist. Recursos Agropecu. 3(7), 143-149.

Camacho, M., K. Arauz, N. Barboza, H. Martínez y J. Arias. 2015. Caracterización de productores de hortalizas orgánicas distribuidas en la gran área metropolitana (GAM), Costa Rica. Agron. Costarr. 39(2), 131-142.

Cisneros, C., M. Sánchez y J. Menjivar. 2016. Influencias de microorganismo solubilizadores de fósforo del suelo y su absorción por plántulas de café. Bioagro 28(2), 95-98.

Díaz, A.L., G. Fischer y S.P. Pulido. 2010. La fibra de coco como sustituto de la turba en la obtención de plántulas de uchuva (Physalis peruviana L.). Rev. Colomb. Cienc. Hortíc. 4(2), 153-162.

Durán, L. y C. Henríquez, 2007. Caracterización química, física y microbiológica de vermicompost producidos a partir de cinco sustratos orgánicos. Agron. Costarr. 31(1), 41-51.

Garbanzo, J. G. y J.R Navarro. 2015. Análisis multicriterio de variables químicas, físicas y biológicas en $10 \mathrm{mez}$ clas de sustratos hortícolas en Guanacaste, Costa Rica. Rev. Intersedes 16(33), 72-81.

Herrera, J., R, Alizaga, E. Guevara y V. Jiménez. 2006. Germinación y crecimiento de la planta. Fisiología de la producción de los cultivos tropicales. Universidad de Costa Rica. San José, Costa Rica.

Jury, W.A., R. Wilford y H. Walter. 1991. Soil physics. $5^{\text {th }}$ ed. John Wiley y Sons, New York, USA.

Lesmes, R., A. Molano, D. Miranda y C. Bernardo. 2007. Evaluación de concentraciones de sal $(\mathrm{NaCl})$ en el agua de riego sobre el crecimiento de lechuga 'Batavia' (Lactuca sativa L.). Rev. Colomb. Cienc. Hortic. 1(2), 222-235. Doi: 10.17584/rcch.2007v1i2.1163

Llorente, M. 2002. Resumen del manual de edafología. Geología. Universidad de Salamanca, Salamanca, España.

MAG. 2012. Memoria anual 2011. Ministerio de Agricultura y Ganadería, San José, Costa Rica.

Meléndez, G. 2004. Slash-and-mulch system: Frijol tapado in Costa Rica. pp. 37-64. En: Eilitta, M., J. Mureithi y R. Derpsch. (eds.). Green manure/cover crop systems of smallholder farmers. Springer, The Netherlands. Doi: 10.1007/1-4020-2051-1

Pérez-Rojas, F., J. León-Quispe y N. Galindo-Cabello. 2015. Actinomicetos aislados del compost y su actividad antagonista a fitopatógenos de la papa (Solanum tuberosum spp. andigena Hawkes). Rev. Mex. Fitopat. 33(2), 116-139.

PIMA. 2012. Tendencias del consumo de frutas, hortalizas pescado y mariscos en las familias de Costa Rica. Programa Integral de Mercadeo Agropecuario. San José, Costa Rica.

Quesada, G. y C. Méndez 2005. Evaluación de sustratos para almácigos de hortalizas. Agron. Mesoam. 16(2), 171-183. Doi: 10.15517/am.v16i2.11870

Restrepo, J. 2001. Elaboración de abonos orgánicos fermentados y biofertilizantes foliares. Experiencias con agricultores en Mesoamérica y Brasil. IICA, Costa Rica.

Richmond, F. 2010. Evaluación de distintas materias primas para la producción de almácigo de tomate. Agron. Costarr. 34(1), 85-91. 
Rodríguez, M., G. Alcántar, A. Aguilar, J. Etchevers y J. Santizó. 1998. Estimación de la concentración de nitrógeno y clorofila en tomate mediante un medidor portátil de clorofila. Terra 16(2), 135-141.

Rodríguez, W. y D. Leihner. 2006. Análisis del crecimiento vegetal. Fisiología de la producción de los cultivos tropicales. Universidad de Costa Rica. San José, Costa Rica.

Rosemeyer, M., N. Viaene, H. Swartz y J. Kettler. 2000. The effect of slash/mulch and alleycropping bean production systems on soil microbiota in the tropics. Appl. Soil Ecol. 15(1), 49-59. Doi: 10.1016/ S0929-1393(00)00071-8
Tombion, L., A. Puerta, L. Barbaro, M. Karlanian, M. Sangiocomo y M. Garbi. 2016. Características del sustrato y calidad de plantines de lechiga (Lactuca sativa L) según dosis de lombricompuesto. Chil. J. Agric. Anim. Sci. 32(2), 59-64. Doi: 10.4067/S0719-38902016000100005

Valverde, A., B. Sarria y J. Monteagudo. 2007. Análisis comparativo de las características fisicoquímicas de la cascarilla de arroz. Sci. Technol. 8(37), 255-260. Doi: 10.22517/23447214.4055

Villalobos, E. 2001. Fisiología de la producción de los cultivos tropicales. Procesos fisiológicos básicos. Universidad de Costa Rica. San José, Costa Rica. 